\title{
A prospective randomised clinical trial of prophylactic antibiotic in caesarean delivery and fetomaternal outcome
}

\section{Apurba Mandal, Shibram Chattopadhyay*, Pragnya Paramita Nayak, Sudakshina Panja, Shritanu Bhattacharyya, Tanmay Mandal}

Department of Obstetrics and Gynecology, Nil Ratan Sircar Medical College, Kolkata, West Bengal, India

Received: 07 December 2017

Accepted: 08 January 2018

\section{*Correspondence:}

Dr. Shibram Chattopadhyay,

E-mail: shibramchatt@gmail.com

Copyright: (C) the author(s), publisher and licensee Medip Academy. This is an open-access article distributed under the terms of the Creative Commons Attribution Non-Commercial License, which permits unrestricted non-commercial use, distribution, and reproduction in any medium, provided the original work is properly cited.

\section{ABSTRACT}

Background: Infectious maternal and perinatal morbidities are 5 to 20 times more in caesarean section when compared to vaginal births. Objective of present study was to assess the rates of maternal and neonatal infectious morbidities following administration of antibiotic before skin incision compared to given after umbilical cord clamping during caesarean delivery.

Methods: 185 pregnant women with gestational periods more than 34 weeks who were prepared for caesarean delivery, randomized to single dose antibiotic given either before skin incision (study group) or after umbilical cord clamping (control group). Primary outcome measures: maternal postoperative infections morbidities. Secondary outcome measures: neonatal infections morbidities with Sick Newborn Care Unit (SNCU) admissions and postoperative hospital stay of mother.

Results: Surgical Site Infections (SSI) and postoperative fever were significantly less in the study group than the control group so also the lesser incidences of endometritis but no statistically significant difference in the incidence of peritonitis and wound dehiscence were observed in both groups. No significant differences were seen in neonatal infectious morbidities and SNCU admission when compared in both groups. There was significantly less mean postoperative hospital stay of mothers in the group who received prophylactic antibiotic pre-incision.

Conclusions: Antibiotic given 30-60 minutes before skin incision significantly decreases maternal postoperative infectious morbidities barring neonate.

Keywords: Caesarean delivery, Postoperative, Prophylactic antibiotic, Surgical site infections

\section{INTRODUCTION}

Infectious maternal and perinatal morbidities are 5 to 20 times more in caesarean section when compared to vaginal births. ${ }^{1}$

Genital tract is most important source of infections particularly when membrane is ruptured and also even if membranes are intact, polymicrobial invasion of intrauterine cavity occurs especially with preterm labour. ${ }^{2}$ The purpose of prophylactic antibiotic in surgeries is not for sterilisation of tissue but for reducing colonization of microorganisms introduced during operation to a level to overcome by patient's immunity. ${ }^{3}$ Broad spectrum antibiotic like cephalosporins are most commonly administered for SSI prophylaxis. ${ }^{4}$ The dosage should be adequate to exceed minimum inhibitory concentration (MIC) for the organism likely to be encountered during the operation. Prophylactic antibiotic during caesarean delivery has usually been given after umbilical cord clamping for apprehension of fetal exposure through placenta if administered earlier. 
However recent studies involving pregnant women including research in nonpregnant populations undergoing operations have suggested that antibiotics given before incision (ideally 30-60 minutes) to allow for optimal concentration at the surgical site reduce SSI by almost half compared to administration during operation or after cord clamping and there is no increase in adverse neonatal outcome. ${ }^{5-8}$

So, a prospective randomized clinical trial was undertaken to notice whether prophylactic antibiotic given before skin incision than after cord clamping, was more effective for preventing infectious morbidities of mother and newborn baby following caesarean delivery.

\section{METHODS}

This prospective randomised study was done at antenatal ward and labour Operation theatre in the department of Obstetrics and Gynaecology, Nilratan Sircar Medical College and Hospital, Kolkata India for the period from April, 2015 to March, 2016. Pregnant women of more than 34 weeks of gestational age admitted in labour and fulfilling eligibility criteria and giving consent were subjected to our study as prematurity is an independent risk for adverse perinatal outcome.

A total of 185 women were randomized after going through exclusion criteria among 200 women as follows:

- $\quad$ patients who are febrile during or prior to screening,

- ruptured membranes more than equal to $18 \mathrm{hrs}$ with or without antibiotic prophylaxis

- $\quad$ patients with chronic diseases like diabeties mellitus, heart disease, renal disease etc.

- patients who have received antibiotics within one week prior to caesarean section for other reasons,

- patients with obstetrics complications like preeclampsia, antepartum haemorrhage,or indications for emergency caesarean deliveries like obstructed labour, deep tranverse arrest, fetal distress etc,

- penicillin or cephalosporin allergy. Those women who were in stable condition enough to delay caesarean section for 90 minutes to 120 minutes in situations like cephalo pelvic disproportion, intrauterine growth retardation with oligohydramnios, malpresentation detected early in labour, were also included in the study.

In present study 200 pregnant women above 34 weeks of gestation admitted in antenatal ward taking clearance from institutional Ethical Committee of NRS Medical College and proper consent were taken from patients. After enrolment, a detailed history regarding age, parity, sociodemographic conditions, period of gestations were taken. Detailed past and present menstrual, medical, surgical and obstetrical histories were also taken. Then thorough general and obstetric examinations were done.9 women were excluded who not meeting inclusion criteria and 6 women were refused to participate. Ultimately 185 women were randomized fulfilling inclusion and exclusion criteria as before and were allocated into two groups: Group A is study group comprising 92 subjects having given ceftrixone injection 1 gram intravenously 30-60 minutes before skin incision after a test done of $100 \mathrm{mg}$ intradermal ceftrixone given slowly over 10 minutes and Group B is the control group comprising 93 subjects having given antibiotic in the same dosage after cord clamping. None of the subjects were lost to follow up and 92 subjects were analyzed in the study group and 93 subjects were analyzed in control group.

The sample size was calculated using previous hospital records of our institution taking $15 \%$ difference in observation of proportions of using prophylactic antibiotics before caesarean delivery having alpha-error as 0.05 (i.e. 1.96) and beta error at power of 80 (i.e. 0.84) resulting minimum members of 77 subjects in each group; thus, validating our present study with adequate member of subjects in the study and control groups.

Standard technique of caesarean section was followed having pfannnenstiel skin incision, two layer closure of uterine wound and non stitching of peritoneum were done by visiting surgeons, RMOs and SRs assisted by JRs. Post operative follow up done for signs of SSI, fever, endometritis, neonatal sepsis, SNCU admission and hospital stay of mother. SSI were diagnosed if there is purulent discharge, erythema and induration of incision site; hematomas, seromas or wound breakdown in the absence of previously described signs were not included. Fever was diagnosed when temperature was more than $100.4^{\circ} \mathrm{F}$ on two occasions $6 \mathrm{hrs}$ apart, excluding first 24 hrs of delivery. Endometritis was elicited if there is presence of fever with lower abdominal or uterine tenderness with tachycardia, leucocytosis, subinvolusion of uterus and foul smelling lochia. High vaginal swab may or may not be positive for organisms. Peritonitis presents as fever, abdominal pain, muscle guarding, rebound tenderness, sinus tachycardia, ileus paralyticus, leucocytosis and abscess in peritoneal cavity. Neonatal sepsis was diagnosed by clinical examination, blood picture, C-reactive protein and positive blood culture as appropriate determined by neonatologist.

Primary outcome measures were postoperative infectious morbidities of mother and secondary outcome measures were neonatal sepsis, SNCU admissions of babies and postoperative hospital stay of mothers.

\section{Statistical analysis}

All clinical and operative observations were recorded by researchers using Microsoft Excel and collected data were analysed by statistical methods, using Quick Calcs, socscistaristics.com having Easy Fisher Exact Test Calculator etc. A P- value less than 0.05 having $95 \%$ confidence interval was considered statistically significant. Normality of data has been tested by ShapiroWilk test. Unpaired t-test has been used to find the 
significance of study parameters between two groups. Chi-square test/Fisher Exact test has been used to find the significance of study parameters on categorical scale between two groups.

\section{RESULTS}

Out of 200 pregnant women enrolled for assessments of eligibility, 15 women were excluded from the study due to either not meeting the inclusion criteria $(n=9)$ or refrained to participate $(n=6)$. So, 185 women were randomized into two groups; 92 in study group (group A) and 93 in the control group (group B). Prophylactic antibiotic (Inj. Ceftrixone 1 gram i.v.) was injected 30-60 minutes prior to skin incision during caesarean delivery in group A and after umbilical cord clamping in group B. No subject was lost to follow-up and hence all women analyzed according to the intention-to-treat protocol.

Table 1: Demographic characteristics.

\begin{tabular}{|c|c|c|c|}
\hline $\begin{array}{l}\text { Characteri } \\
\text { stics }\end{array}$ & $\begin{array}{l}\text { Study group } \\
(\mathrm{n}=92)\end{array}$ & $\begin{array}{l}\text { Control } \\
\text { Group } \\
(n=93)\end{array}$ & $\begin{array}{l}\text { P-value } \\
(95 \% \mathrm{CI})\end{array}$ \\
\hline $\begin{array}{l}\text { Age in } \\
\text { years } \\
(\text { mean } \pm S D)\end{array}$ & $\begin{array}{l}24.32 \pm 3.01 \\
(\mathrm{t}=0.1327 \\
\mathrm{df}=183 \\
\mathrm{SE}=0.452)\end{array}$ & $24.26 \pm 3.14$ & $\begin{array}{l}0.8946 * \\
(-0.8324 \text { to } \\
0.9524)\end{array}$ \\
\hline $\begin{array}{l}\text { BMI } \\
(\text { mean } \pm S D)\end{array}$ & $\begin{array}{l}24.81 \pm 2.15 \\
(\mathrm{t}=1.2107 \\
\mathrm{df}=183 \\
\mathrm{SE}=0.322\end{array}$ & $25.20 \pm 2.23$ & $\begin{array}{l}0.2276^{*} \\
(-0.0255 \text { to } \\
0.2455)\end{array}$ \\
\hline $\begin{array}{l}\text { Gestational } \\
\text { age in } \\
\text { weeks } \\
(\text { mean } \pm \text { SD) }\end{array}$ & $\begin{array}{l}37.62 \pm 1.54 \\
\{t=1.2823 \\
d f=183 \\
S E=0.234\end{array}$ & $37.92 \pm 1.64$ & $\begin{array}{l}0.2014 * \\
(-0.7616 \text { to } \\
0.1616)\end{array}$ \\
\hline \multicolumn{4}{|c|}{ Indications for LSCS } \\
\hline Emergency & $52(56.52 \%)$ & $58(62.37 \%)$ & $0.0822^{* *}$ \\
\hline Elective & $40(43.48 \%)$ & $35(37.63 \%)$ & $0.0843^{* *}$ \\
\hline
\end{tabular}

Demographic characteristics of women in both groups were identical as shown in Table 1 in relation to age $(24.32 \pm 3.01$ vs $24.26 \pm 3.14, \mathrm{P}=0.8946,95 \% \mathrm{CI}=-0.8324$ to 0.9524$)$, BMI $(24.81 \pm 2.15$ vs $25.20 \pm 2.23, \mathrm{P}=0.2276$, $95 \% \mathrm{CI}=-0.0255$ to 0.2455$)$, gestational age in weeks $(37.62 \pm 1.54$ vs $37.92 \pm 1.64, \mathrm{P}=0.2014,95 \% \mathrm{CI}=-0.7616$ to 0.1616$)$ and indication of caesarean deliveries also and they are statistically not significant $(\mathrm{p}>0.05)$.

In Table 2 the prospective maternal infections morbidities showed statistically significant difference in between the two groups with espect to fever from 2 nd post operative day $(5.43 \%$ vs $21.50 \%, \mathrm{P}=0.020)$,SSI $(3.26 \%$ vs $8.60 \%$, $\mathrm{P}=0.0039)$ and endometritis $(5.26 \%$ vs $19.35 \%$, $\mathrm{P}=0.00075 \%)$ but not significant whene wound dehiscence $(1.08 \%$ vs $2.15 \%, \mathrm{P}=0.0657)$ and peritonitis (1.085 vs $3.22 \%, \mathrm{P}=0.0694)$ were considered.
Table 2: Postoperative maternal infectious morbidities.

\begin{tabular}{|llll|}
\hline Outcome & $\begin{array}{l}\text { Study } \\
\text { group } \\
(\mathbf{n = 9 2})\end{array}$ & $\begin{array}{l}\text { Control } \\
\text { group } \\
(\mathbf{n = 9 3 )}\end{array}$ & $\begin{array}{l}\text { P- } \\
\text { value* }\end{array}$ \\
\hline $\begin{array}{l}\text { Fever (From 2nd } \\
\text { post-operative day) }\end{array}$ & $5(5.43 \%)$ & $20(21.50 \%)$ & 0.0020 \\
\hline SSI & $9(3.26 \%)$ & $25(8.60 \%)$ & 0.0039 \\
\hline Wound dehiscence & $1(1.08 \%)$ & $2(2.15 \%)$ & 0.0657 \\
\hline Endometriosis & $3(3.26 \%)$ & $18(19.35 \%)$ & 0.0007 \\
\hline Peritonitis & $1(1.08 \%)$ & $3(3.22 \%)$ & 0.0694 \\
\hline
\end{tabular}

There was no significant difference in neonatal outcomes as shown in table 3 when the following parameters were taken into account like sepsis, fever, poor feeding, birth asphyxia, SNCU admissions; as $\mathrm{P}=>0.05$ between the groups. But mean postoperative study of mothers in hospital was statistically significant by less in the study group than the control group $(5.05=-1.67$ vs $7.11=-1.55$, $\mathrm{P}=0.0001,95 \% \mathrm{CI}=-2.4756$ to -1.6444$)$.

Table 3: Neonatal infectious morbidities, SNCU admissions and postoperative hospital stay of mother.

\begin{tabular}{|c|c|c|c|}
\hline outcome & $\begin{array}{l}\text { Study } \\
\text { group } \\
(n=92)\end{array}$ & $\begin{array}{l}\text { Control } \\
\text { group } \\
(\mathbf{n}=93)\end{array}$ & Pvalue \\
\hline Sepsis & $3(3.26 \%)$ & $5(5.37 \%)$ & $0.0693^{*}$ \\
\hline Fever & $2(2.17 \%)$ & $3(3.22 \%)$ & $0.0656^{*}$ \\
\hline Poor feeding & $3(3.26 \%)$ & $4(4.30 \%)$ & $0.0655^{*}$ \\
\hline Birth asphyxia & $1(1.08 \%)$ & $1(1.07 \%)$ & $0.0620 *$ \\
\hline $\begin{array}{l}\text { SNCU } \\
\text { admission }\end{array}$ & $6(6.52 \%)$ & $\begin{array}{l}10 \\
(10.75 \%)\end{array}$ & $0.0766^{*}$ \\
\hline $\begin{array}{l}\text { Post-operative } \\
\text { hospital stay of } \\
\text { mother } \\
(\text { mean } \pm \text { SD) }\end{array}$ & $\begin{array}{l}5.05 \pm 1.67 \\
(t=9.7805 \\
d f=183 \\
S E=0.211\end{array}$ & $7.11 \pm 1.15$ & $\begin{array}{l}0.0001 * * \\
(-2.4756 \text { to } \\
-1.6444)\end{array}$ \\
\hline
\end{tabular}

*denotes Mid-Pexact and **denotes P-value (two tailed).

\section{DISCUSSION}

Both elective and emergency caesarean deliveries are benefited when prophylactic antibiotic is used - long acting, less costly and having fewer side effects is preferred.

A cephalosporin namely ceftrixone is chosen for effective prophylaxis against post operative infection morbidities following caesarean sections in many previous clinical trials. ${ }^{9-11}$ Present study determines the difference of infectious morbidities in mothers and neonates between pre operative use of prophylactic antibiotic and the use after cord-clamping during caesarean delivery.

The demographic characteristics were comparable in two groups with no significant differences in relation to mean age in years $(\mathrm{P}=0.8946 ; 95 \% \mathrm{CI}$ of -0.8324 to 0.9524$)$, BMI $(\mathrm{P}=0.2276 ; 95 \% \mathrm{CI}$ of -0.7616 to 0.1616$)$. These results are consistent with the results of studies conducted 
previously by Thigpen et al, Sullivan et al, Bhattacharjee $\mathrm{N}$ et al and also Alakananda et al. ${ }^{12-15}$ There was also no statistically significant difference between groups found in indication for LSCS in emergency $(\mathrm{P}=0.0822)$ and elective $(\mathrm{P}=0.0813)$. Similar study was done by Thigpen et al previously showing no significant differences in indication for $\operatorname{LSCS}(\mathrm{P}=0.54) .{ }^{12}$

In present study only $5.43 \%$ of patients developed fever from $2^{\text {nd }}$ postoperative day onwards in the study group than in the control group where it was $21.5 \%$ showing a significant difference $(\mathrm{P}=0.0020)$. In the study conducted by Bhattacharya et al, $33 \%$ of the patients who received antibiotic after cord clamping had more postoperative fever than in $26 \%$ of the patient with fever who received antibiotic before skin incision. ${ }^{14}$ Baaqaeel et al found that there was nonsignificant reduction in maternal febrile morbidity in group who received preoperative antibiotic. ${ }^{16}$ Smaill FM et al conducted RCT found that there was decreased incidence of maternal febrile morbidity in the group who received pre operative antibiotic. $^{17}$

In study conducted by Kalarnjini $\mathrm{S}$ et al no significant difference in fever was found. In present study complications like SSI in terms of induration, erythema and wound discharge were seen in $3.26 \%$ in study group and $8.60 \%$ in the control group with significant differences $(\mathrm{P}=0.0039) .{ }^{18}$ Similar results were found in the studies conducted by Sullivan et al, Kaimal et al, Owens et al, Lamont RF et al, Alakanada et al, but insignificant results were found in studies conducted by Baaqeel et al, Heesen et al, Sun $\mathrm{J}$ et al and Zhang $\mathrm{C}$ at el. ${ }^{7,13,15,19-23}$

Endometritis was found in $3.26 \%$ of the patients in the pre-incision group than $19.35 \%$ of the patients in the control group showing statistically significant difference $(\mathrm{P}=0.0007)$. In the studies conducted by Sullivan et al, Costantine MM et al, Kaimal MD et al, Baaqeel et at, Heesen et al, Bhattacharjee N et al, Sun J et al, Mackeen $\mathrm{AD}$ et al, Smaill FM et al; the incidence of postpartum endometritis was reduced in the group who received antibiotic pre-incision as compared to group who received antibiotic after cord clamping. 6,13,14,16,17,19,21,22,24,25 But Thigpen et al and Zhang $\mathrm{C}$ proposed no significant difference in postoperative endometritis in both groups. ${ }^{12,23}$

Wound dehiscence occurred insignificantly in both the groups $(\mathrm{P}=0.0657)$ as well as the incidence of peritonitis $(\mathrm{P}=0.0694)$. Similar results happened in the study conducted by Bhattacharjee $\mathrm{N}$ et al $(\mathrm{P}=0.288$ for wound dehiscence). ${ }^{14}$ Young $\mathrm{BC}$ et al found that infectious morbidity fell from $5.4 \%$ to $2.5 \%$ when antibiotic given before skin incision. ${ }^{26}$

Costantine $\mathrm{MM}$ et al found decreased rates of total infectious morbidity $(\mathrm{P}=0.15)$ in the group who received pre incision antibiotic. ${ }^{6}$ Brown $\mathrm{J}$ et al, Mackeen AD et al, Smaill FM et al, Sullivan et al showed decreased rates of maternal infectious morbidity in pre incision group..$^{24,25,27}$ Witt $\mathrm{A}$ et al and Zhang $\mathrm{C}$ et al found no significant difference in total infectious morbidity in both groups. ${ }^{23,28}$

Present study revealed neonatal morbidities like neonatal sepsis $(\mathrm{p}=0.0693)$, neonatal fever $(\mathrm{P}=0.0656)$, neonatal poor feeding $(\mathrm{P}=0.0655)$, birth asphyxia $(0.0620), \mathrm{SNCU}$ admission $(\mathrm{P}=0.0766)$ had no significant differences in both group; results were similar in the previous studies also as mentioned in above paragraph. Mean hospital stay of mothers was significantly less in study group $(\mathrm{P}=0.0001)$ which is consistent with other studies as of Smaill $\mathrm{F}$ et al and Bhattarjee $\mathrm{N}$ et al. ${ }^{14,17}$

The sample size was medium but significant. Pharmacokinetics of antibiotic in individual patient could not be compared. Intraoperative and immediate post operative blood loss was not estimated though blood transfusion was not required in any patient in both of the groups

\section{CONCLUSION}

Prophylactic administration of antibiotic at 30-60 minutes before the incision of skin during caesarean section have better maternal outcome when infectious morbidities and postoperative hospital stay were accounted without any difference in neonatal outcome than antibiotic used after umbilical cord clamping after delivery of the baby.

\section{ACKNOWLEDGMENTS}

Authors would like to thank the involvement of the onduty doctors, nurses and other supporting staffs of the antenatal ward, labour room and OT in the Department of Obstetrics and Gynecology of NRSMCH, West Bengal, India who have done immense help in doing the present study.

\section{Funding: No funding sources Conflict of interest: None declared \\ Ethical approval: The study was approved by the Institutional Ethics Committee}

\section{REFERENCES}

1. Declercq E, Barger M, Cabral HJ, Evans SR, Kotelchuck M, Simon C, et al. Maternal outcomes associated with planned primary Caesarean births compared with planned vaginal births. Obstet Gynecol. 2007;109:669-77.

2. Watts DH, Krohn MA, Hillier SL, Eschenbach DA. The Association of Occult Amniotic fluid infection with Gestational age and neonatal outcomes among women in pre-term labour. Obstet Gynaecol. 1992;79:351-7.

3. Mangram AJ, Horan TC, Pearson ML, Silver LC, Jarvis WR. Guideline for the prevention of surgical site infection. 1999. Centre for Disease Control and Prevention (CDC) Hospital Infection Control Practices Advisory Committee. Am J Infect Control. 1999;27:97134. 
4. Kaiser AB. Overview of cephalosporin prophylaxis. Am J Surg. 1988;155(5A):52-5.

5. Tita AT, Rouse DJ, Blackwall S, Sadde GR, Spong CT, Andrews WW. Emerging concepts in antibiotic prophylaxis for caesarean delivery: a systemic review. Obstet Gynecol. 2009;113:675-82.

6. Costantine MM, Rahman M, Ghulmiyah L, Byers BD, Longo $\mathrm{M}$, Wen $\mathrm{T}$, et al. Timing of perioperative antibiotics for caesarean delivery: a meta-analysis. Am J Obstet Gynecol. 2008;199:301.

7. Owens SM, Brozanski BS, Meyn LA, Wiesenfeld HC. Antimicrobial prophylaxis for caesarean delivery before skin incision. Obstet Gynecol. 2009;114:573-9.

8. National Institute for Health and Clinical excellence. CG132 Caesarean Section. Available at http://guidance.nice.org.uk/CG132.

9. Scully BE, Fu KP, New HC. Pharmacokinetics of Ceftriaxone after intravenous infusion and intramuscular injection. Am J Med. 1984;77:112-6.

10. Adam I, Adam ES, Gerais AS. Randomized trial of Ceftriaxone prophylaxis in elective caesarean section. Saudi Med J. 2005 Mar;26(3):500-1.

11. Chalkiadakis, Gonianakis C, Tsatsakis A, Tsakalof A, Michalodimitrakis M. Pre-Incisional Single-Dose Ceftriaxone for the prophylaxis of surgical wound infection. Am J Surg. 1995;170:353-5.

12. Thigpen BD, Hood WA, Chauhan S, Bufkin L, Bofill J, Maggan E et al. Timing of prophylactic administration in the uninfected labouring gravida : a randomized clinical trial. Am J Obstet Gynecol. 2005 June;192(6):1868-71.

13. Sullivan SA, Smith T, Chang E, Hulsey T, Vandorsten JP, Soper D. Administration of Cefazolin at cord clamping in preventing post caesarean infectious morbidity; A randomized controlled trial. Am J Obstet Gynecol. 2007;196:455e1-455.e5.

14. Bhattacharjee N, Saha SP, Patra KK, Mitra U, Ghoshroy SC. Optimal timing of prophylactic antibiotic for CD:A randomised comparative study. J Obstet Gynecol Res. 2013 Dec;39(12).

15. Alaknanda, Das GC, Gautam H. Optimal timing of perioperative antibiotic in caesarean section and risk of postpartum and neonatal infections. She J App Med Sci. 2015; 3(7B):2544-51.

16. Baaqeel H, Baaqeel R. Timing of administration of prophylactic antibiotic of caesarean section: a systemic review and meta-analysis. BJOG. 2013;120(6).

17. Smaill FM, Gyte GM. Antibiotic prophylaxis versus no prophylaxis for preventing infection after caesarean section. Cochrane database Syst Rev. 2010;(1):CD 007482.

18. Kalaranjini S, Veena P, Rani R. Comparision of administration of simple dose Ceftriaxone for elective caesarean section before skin incision and after cord clamping in preventing post-operative infectious morbidity. Arch Gynecol Obstet. 2013 Dec;288(6):1263-8.
19. Kaimal AJ, Zlatnik MG, Chang YW, Thiet MP, Connatty E, Creedy $\mathrm{P}$ et al. Effects of a change in policy regarding the timing of prophylactic antibiotics on the rate of post-caesarean delivery surgical site infections. Am J Obstet Gynecol. 2008;199:310.el310.e5.

20. Lamont RF, Sobel J, Kusanovic JP, Vaisbuch E, Mazaki-Tovi S, Kim SK et al. Current Debate on the use of Antibiotic prophylaxis for caesarean section. BJOG. 2011 Jan;11(2):193-201.

21. Heesen M, Klohr S, Rossaint R, Allegeaert A, Deprest $\mathrm{J}$, VanDe VM et al. Concerning the timing of antibiotic administration in women undergoing caesarean: a systematic review and metanalysis. BMJ Open. 2013;3:002028.

22. Sun J, Ding M, Liu J, Li Y, Sun X, Liu T et al. Prophylactic administration of Cefazolin prior to skin incision VS Antibiotics at cord clamping in preventing post-caesarean infections morbidity: A Systematic review and meta-analysis of randomized controlled trials. Gynecol Obstet Invest. 2013;75:175-8.

23. Zhang C, Zhang L, Liu X, Zhang Li, Zeng Z, Li L et al. Timing of antibiotic prophylaxis in elective caesarean delivery: A multicentre randomized controlled trial and meta-analysis. PLoS One. 2015;10(7):e0129434.

24. Mackeen AD, Packard RD, Ota E, Berghella V, Baxter JK. Timing of intravenous prophylactic antibiotics for preventing postpartum infections morbidity in women undergoing caesarean delivery. Cochrane Database Syst Rev. 2014 Dec;(12):CD 009516.

25. Smaill FM, Grivell RM. Antibiotic prophylaxis VS no prophylaxis for preventing infections after caesarean section. Cochrane Database Syst Rev. 2014 Oct;( 10):CD007482.

26. Young BC, Hacker MR, Dodge LE, Golen TH. Timing of antibiotic administration and infectious morbidity following caesarean delivery: incorporating policy change into workflow. Arch Gynecol Obstet. 2012 May;285(5):1219-24.

27. Brown J, Thompson M, Sinnya S, Jeffery A, Costade C, Woods C, Howat P. Pre-incision antibiotic prophylaxis reduces the incidence of post-caesarean surgical site infection. Journal Hospital Infect. 2013;83:68-70.

28. Witt A, Doner M, Petricevic L, Bergger A, Germann P, Heinze $\mathrm{G}$ et al. Antibiotic prophylaxis before surgery vs cord clamping in elective caesarean delivery: a double blind, prospective, randomized, placebo controlled trial. Arch Surg. 2011;146:1404-9.

Cite this article as: Mandal A, Chattopadhyay $\mathrm{S}$, Nayak PP, Panja S, Bhattacharyya S, Mandal T. A prospective randomised clinical trial of prophylactic antibiotic in caesarean delivery and fetomaternal outcome. Int J Reprod Contracept Obstet Gynecol 2018;7:639-43. 